
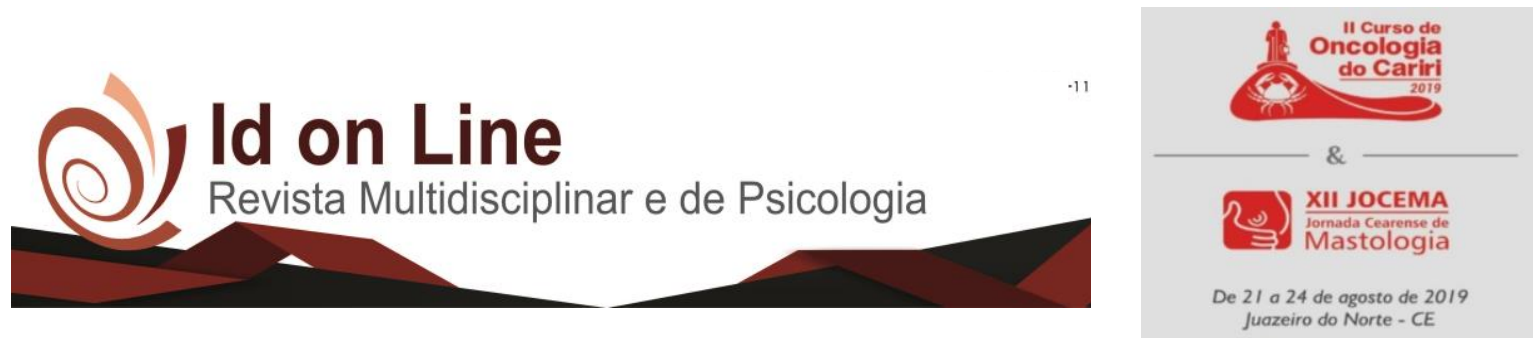

DOI: 10.14295/idonline.v13i46.2001

Resumo

\title{
TUMOR NEUROENDÓCRINO EM APÊNDICE ILEOCECAL: RELATO DE CASO
}

\author{
Pedro Walisson Gomes Feitosa ${ }^{1}$; Sávio Samuel Feitosa Machado ${ }^{2}$
}

\begin{abstract}
Introdução: As neoplasias do apêndice ileocecal ocorrem em torno de $1 \%$ das apendicectomias e $0,5 \%$ dos tumores intestinais diagnosticados. $\mathrm{O}$ quadro surge com uma incidência estimada na literatura de 0,15/100.000/ano, mais frequentemente no sexo feminino (2:1) na faixa etária dos 40-50 anos. Geralmente, são diagnosticados incidentalmente após apendicectomias, estimando-se que existam cerca de 3 casos em cada 1000 apendicectomias. Além disso, estes desenvolvimentos neoplásicos não se apresentam com clínica específica, sendo comumente abordados como quadro agudo abdominal. Objetivo: Apresentar o estudo de achados anatomopatológicos e histológicos de tumor neuroendócrino do apêndice ileocecal após quadro clínico de apendicite aguda. Relato de Caso: Homem de 46 anos, sexo masculino, recorreu ao Serviço de Urgência com queixa de dor abdominal localizada na fossa ilíaca direita e sinais de irritação peritoneal. Após diagnóstico de apendicite aguda, o paciente foi submetido a apendicectomia, evidenciando sinais intraoperatórios de apendicite avançada e peritonite regional. Nesse ínterim, o material foi enviado para estudo patológico. No exame macroscópico notou-se área de $1,9 \mathrm{~cm}$ de comprimento, endurecida, de formas irregulares e amareladas, no terço distal do apêndice. A análise histopatológica confirmou amplo tecido necrótico e neoplásico com presença de ilhas invasivas de células epitelioides arredondadas e monótonas, invasão de tecido neural, angiolinfático e adiposo, sugerindo irradiação para mesoapêndice, em estado mitótico. Os achados evocam para a malignidade neoplásica. Ademais, foi denotada uma margem tecidual comprometida, confirmando a persistência de neoplasia no paciente mesmo após a abordagem cirúrgica, recomendando a continuidade do tratamento. Conclusão: Os tumores neuroendócrinos do apêndice ileocecal são raros e o prognóstico é geralmente favorável. A apendicectomia simples é o tratamento cirúrgico de rotina e proporciona a cura na maioria dos casos. Portanto, frisa-se a importância do envio de materiais coletados para análise do patologista, uma vez que esta auxilia na avaliação clínica, diagnóstico etiológico, luto familiar em casos de mortalidade, além de nortear a conduta médica na evolução do caso.
\end{abstract}

Palavras-chave: Tumor neuroendócrino; Apendicite aguda.

\section{Referências}

DEANS GT, SPENCE RAJ - Neoplastic lesions of the appendix. Br J Surg 1995; 82: 299-306;

LOPES JUNIOR, Ascêncio Garcia; SAQUETI, Eufânio E.; CARDOSO, Luciene T. Q.. Tumor do apêndice vermiforme. Rev. Col. Bras. Cir., Rio de Janeiro, v. 28, n. 3, p. 228-229, June 2001 .

\footnotetext{
${ }^{1}$ Acadêmico de Medicina pela Universidade Federal do Cariri. gomesfeitosa.walisson@outlook.com

${ }^{2}$ Médico Patologista na Faculdade de Medicina da Universidade Federal do Cariri 